\title{
Article
}

\section{Bovine Serum Albumin Adsorbed PGA-co- PDL Nanocarriers for Vaccine Delivery via Dry Powder Inhalation}

Kunda, Nitesh K., Alfagih, Iman M., Dennison, Sarah Rachel, Tawfeek, Hesham M., Somavarapu, Satyanarayana, Hutcheon, Gillian A. and Saleem, Imran Y.

Available at http://clok.uclan.ac.uk/11852/

Kunda, Nitesh K., Alfagih, Iman M., Dennison, Sarah Rachel ORCID: 00000003-4863-9607, Tawfeek, Hesham M., Somavarapu, Satyanarayana, Hutcheon, Gillian A. and Saleem, Imran Y. (2015) Bovine Serum Albumin Adsorbed PGA-Co-PDL Nanocarriers for Vaccine Delivery via Dry Powder Inhalation. Pharmaceutical Research, 32 (4). pp. 1341-1353. ISSN 0724-8741

It is advisable to refer to the publisher's version if you intend to cite from the work. http://dx.doi.org/10.1007/s11095-014-1538-5

For more information about UCLan's research in this area go to http://www.uclan.ac.uk/researchgroups/ and search for < name of research Group>.

For information about Research generally at UCLan please go to http://www.uclan.ac.uk/research/

All outputs in CLoK are protected by Intellectual Property Rights law, including Copyright law. Copyright, IPR and Moral Rights for the works on this site are retained by the individual authors and/or other copyright owners. Terms and conditions for use of this material are defined in the policies page. 
Bovine Serum Albumin Adsorbed PGA-co-PDL Nanocarriers forVaccineDeliveryviaDryPowder Inhalation

Nitesh K. Kunda \& Iman M. Alfagih \& Sarah Rachel Dennison \& Hesham M. Tawfeek \& Satyanarayana Somavarapu \& Gillian A. Hutcheon \& Imran Y.Saleem

\begin{abstract}
Purpose Dry powder vaccine delivery via the pulmonary route has gained significant attention as an alternate route to parenteral delivery. In this study, we investigated bovine serum albumin (BSA) adsorbed poly(glycerol adipate-co- $\omega$-pentadecalactone), PGA-co-PDL polymeric nanoparticles (NPs) within L-leucine (L- leu) microcarriers for dry powder inhalation.

Methods NPs were prepared by oil-in-water single emulsion-solvent evaporation and particle size optimised using Taguchi's design of experiment. BSA was adsorbed onto NPs at different ratios at room temperature. The NPs were spray-dried in aque- ous suspension of L-leu (1:1.5) using a Büchi-290 minispray dryer. The resultant nanocomposite microparticles (NCMPs) were characterised for toxicity (MTTassay), aerosolization (Next Generation Impactor), in vitro release study and BSA was characterized using SDS-PAGE and CD respectively.

Results NPs of size $128.50 \pm 6.57 \mathrm{~nm}$, PDI $0.07 \pm 0.03$ suitable for targeting lung dendritic cells were produced. BSA adsorption for $1 \mathrm{~h}$ resulted in $10.23 \pm 1.87 \mu \mathrm{g}$ of protein per $\mathrm{mg}$ of NPs. Spray-drying with L-leu resulted in NCMPs with $42.35 \pm 3.17 \%$ yield. In vitro release study at $37^{\circ} \mathrm{C}$ showed an initial burst release of $30.15 \pm 2.33 \%$ with $95.15 \pm 1.08 \%$ over $48 \mathrm{~h}$. Aerosolization studies indicated fine particle fraction $(\mathrm{FPF} \%$ ) dae $<4.46 \mu \mathrm{m}$ as $76.95 \pm 5.61 \%$ and mass median aerodynamic diameter (MMAD) of $1.21 \pm 0.67 \mu \mathrm{m}$. The cell viability was $87.01 \pm 14.11 \%$ (A549 cell line) and $106.04 \pm 21.14 \%$ (16HBE14ocell line) with L-leu based NCMPs at $1.25 \mathrm{mg} / \mathrm{ml}$ concentration after $24 \mathrm{~h}$ treatment. The SDS-PAGE and CD confirmed the primary and secondary structure of the released BSA.

Conclusions The results suggest that PGA-co-PDL/L-leuNCMPs may be a promising carrier for pulmonary vaccine delivery due to excellent BSA adsorption and aerosolization behaviour.
\end{abstract}

KEY WORDS dry powder inhalation · nanoparticles · pulmonary delivery · spray drying · vaccines

$\begin{array}{ll}\text { ABBREVIATIONS } \\ \text { APCs } & \text { Antigen presenting cells } \\ \text { BSA } & \text { Bovine serum albumin } \\ \text { DCs } & \text { Dendritic cells } \\ \text { DoE } & \text { Design of experiment } \\ \text { LN } & \text { Lymph node } \\ \text { NPs } & \text { Nanoparticles } \\ \text { NCMPs } & \text { Nanocompositemicroparticles } \\ \text { PGA-co-PDL Poly(glycerol adipate-co-(w-pentadecalactone) } \\ \text { PLA } & \text { Polylactide or poly-L-lactic acid } \\ \text { PLGA } & \text { Poly lactic-co-glycolic-acid } \\ \text { PVA } & \text { Polyvinyl alcohol } \\ \text { SD } & \text { Spray-drying }\end{array}$




\section{INTRODUCTION}

Vaccination refers to induction of an immune response using antigens coupled with adjuvants for generating a protective immunity against plausible future infections $(1,2)$. Traditional vaccines are often administered via the parenteral route requiring infrastructure such as cold-chain, sterilized water for reconstitution of dry powder vaccines and trained medical personnel. Lack of these facilities in low and middle income countries (LMICs) is leading to many eligible children and adults not getting vaccinated (3). Moreover, the majority of the potential vaccines in development employ purified subunits or recombinant proteins that are often poorly immunogenic thus needing adjuvants and effective delivery systems to generate an optimal immune response $(1,2)$. To address these issues, particulate delivery systems and non-invasive routes of delivery are being investigated. The pulmonary route has gained significant attention for delivery of vaccines as it is one of the main entry portals for pathogens, and can address some of the challenges such as invasiveness, cold-chain requirement, and stability of the antigen by delivering the antigen as a dry powder (3).

Biodegradable polymeric nanoparticles (NPs) have gained significant attention and are largely being explored as delivery vehicles for delivery of peptides, proteins, antigens, DNA etc. (3-5). These polymers offer controlled or sustained drug release, biocompatibility with surrounding cells and tissues, degrade into low molecular weight non-toxic products and act as adjuvants helping in generating cellular and humoral immune responses $(1,3,6)$. In this current investigation we aim to use poly(glycerol adipate-co- $\omega$ pentadecalactone), PGA-co-PDL, a biodegradable polyester polymer, that has extensively been studied by our group for delivery of both small molecule and model drugs (dexamethasone phosphate, ibuprofen, sodium fluorescein), and large molecule drugs ( $\alpha$-chymotrypsin, DNase I) (7-10).

In these biodegradable polymeric nanoparticulate formu- lations, the vaccine antigens (i.e. proteins, peptides etc.) are either adsorbed onto the surface or encapsulated within the particles (3). Encapsulated antigens are protected by polymeric NPs and their release can be modified by tailoring the properties of the polymers. Adsorbed antigen, however, offers enhanced stability and activity over the encapsulated antigen by avoiding contact with organic solvents employed during particle preparation steps (11-13).

Recent strategies for effective vaccine delivery have been to target the dendritic cells (DCs), the true professional antigen presenting cells (APCs) (14). DCs have the exceptional ability to internalize, and in lymph nodes (LNs) they process and present antigens through major histocompatibility complex (MHC) class I and II pathways thereby activating naïve T- cells resulting in induction of a strong immune response $(3,14,15)$. A study conducted by Manolova et al. indicates the importance of particle size in determining the uptake by DCs, where it was shown that upon intracutaneous injection of polystyrene beads of varying sizes, large particles $(500-2,000 \mathrm{~nm}$ ) associated with DCs from the site of injection whereas small particles (20-200 nm) drained freely to the LNs and were present in LN resident DCs (15). In addition, Kim et al. have shown that uptake of $200 \mathrm{~nm}$ sized NPs by bone marrow DCs to be more than that of $30 \mathrm{~nm}$ sized NPs (16). Furthermore, Foged et al. has shown that particle size of $500 \mathrm{~nm}$ or below were preferred and have shown fast and efficient up take by human DCs derived from blood (17). The above literature suggests that smaller particles of 200 to $500 \mathrm{~nm}$ could effectively be up taken by DCs and thus generates a stronger immune response compared to vaccine alone. However, these studies cannot be directly compared to lung DCs but owing to the lack of information on the effect of NP size on uptake by lung DCs the same can be assumed.

In this study, the Taguchi L18 orthogonal array design of experiment(DoE) was used to optimize the formulation parameters to achieve NPs $(\sim 150 \mathrm{~nm})$ for targeting the lung DCs. The literature suggests that factors such as molecular weight(MW) of the polymer, organic solvent, aqueous phase, sonication time and stirrer speed have an influence on the size of the resultant NPs (18-20) and these were evaluated using the experimental design. As a dry powder, the nanosized particles cannot be directly used for inhalation as their size is too small and it is expected that majority of the inhaled dose will be exhaled depositing very minimal doses in the lung(21). Thus, these NPs are formulated into nanocomposite microparticles 
(NCMPs) using additives such as lactose (22), L-leucine (L-leu) (22,23), trehalose (24), mannitol (24) by various manufacturing techniques such as freeze drying, spray drying (SD), spray-freeze drying or super- critical fluid technologies $(3,25)$. The NCMPs in the size range of 1 to $5 \mu \mathrm{m}$ in diameter are reported to be deposited in the respirable airways and periphery of the lung (26). The additives used to form NCMPs dissolve upon encountering the respiratory environment thereby releasing the NPs (27).

In this project, we aim to produce PGA-co-PDL NPs of optimum size to be effectively taken up by the DCs, surface adsorb a model protein, bovine serum albumin (BSA) and formulate into nanocomposite microparticles (NCMPs) using L-leu as a carrier for delivery via dry powder inhalation.

\section{MATERIALS AND METHODS}

\section{Materials}

Dichloromethane (DCM) was purchased from BDH, laboratory supplies, UK. Novozyme 435 (a lipase from Candida antartica immobilized on a microporous acrylic resin) was purchased from Biocatalytics, USA. Acetonitrile (HPLC grade), albumin tagged with fluorescein isothiocyanate (FITC-BSA), bovine serum al- bumin (BSA, MW $67 \mathrm{KDa}$ ), phosphate buffered saline (PBS, pH 7.4) tablets, poly(vinyl alcohol) (PVA, MW 9-10 KDa, 80\%), trifluoroacetic acid (TFA, HPLC grade), RPMI-1640 medium with Lglutamine and $\mathrm{NaHCO}$, thiazoly blue tetrazo- lium bromide(MTT), tween $80^{\circledR}$ and $\omega$-pentadecalactone were obtained from Sigma-Aldrich, UK. L-leucine (L-leu) was purchased from BioUltra, Sigma, UK. Seventy-five $\mathrm{cm}^{2}$ /tissue ulture flasks with vented cap, 96-well flat bottom plates, ace- tone, antibiotic/ antimycotic solution (100X), dimethyl sulfoxide (DMSO) were purchased from Fisher Scientific, UK. Divinyladipate was obtained from Fluorochem, UK. Fetal calf serum (FCS) heat inactivated was purchased from Biosera UK. poly(glycerol adipate-co- $\omega$-pentadecalactone) (PGA-co-PDL), MW of 14.7, 24.0 KDa was synthesized in our laboratory at LJMU and micro BCA ${ }^{\mathrm{TM}}$ protein assay kit was purchased from Thermo Scientific, UK. A549 cell line was purchased from ATCC. 16HBE140- cells were obtained from Dr Dieter Gruenert from the California Pacific Medical Center, University of California San Francisco, USA.

\section{Polymer Synthesis}

The PGA-co-PDL polymer of MW of 14.7, 24.0 KDa was synthesized in our laboratory via enzyme catalyzed co- polymerization of three monomers as described by Thompson et al. (28). The synthesized linear polyester was characterized by gel permeation chromatography, GPC (Viscotek TDA Model 300 using OmniSEC3 operating software), pre-calibrated with poly- styrene standards (polystyrene standards kit, Supelco, USA), and ${ }^{1} \mathrm{H}-\mathrm{NMR}$ spectroscopy (Bruker AVANCE $300 \mathrm{MHz}$, Inverse probe with B-ACS 60, Auto sampler with gradient chemming) as describedby Thompsonetal.(28).

\section{Preparation of Nanopartides}

PGA-co-PDL NPs were fabricated using a modified oil-in- water $(\mathrm{o} / \mathrm{w})$ single emulsion solvent evaporation method (29). Briefly, $200 \mathrm{mg}$ PGA-co-PDL polymer (MW 14.7 KDa) (and Nile Red, NR $0.5 \mathrm{mg}$ for characterization of protein adsorp- tion onto the surface of PGA-co-PDL via confocal microscopy) was dissolved in $2 \mathrm{ml} \mathrm{DCM}$ and probe sonicated (20 $\mu \mathrm{m}$ amplitude) upon addition to 5 $\mathrm{ml}$ of $10 \% \mathrm{w} / \mathrm{v}$ poly(vinyl alcohol) (PVA) ( $1^{\text {st }}$ aqueous solution) for 2 min to obtain an emulsion. This whole process was performed using ice. This was immediately added drop wise to $20 \mathrm{ml}$ of $2^{\text {nd }}$ aqueous solution $(0.75 \% \mathrm{w} / \mathrm{v}$ PVA $)$ under magnetic stirring at a speed of $500 \mathrm{RPM}$. The whole mixture 
was left stirring at room temperature for $3 \mathrm{~h}$ to facilitate the evaporation of DCM. The particle size, PDI and zeta-potential were then characterised as mentioned in "Nanoparticle Characterization" Section. The NP suspensions were collected by centrifugation (78,000 g, $40 \mathrm{~min}, 4^{\circ} \mathrm{C}$ ) and surface adsorbed with protein as indicated in "Protein Adsorption” Section.

\section{Taguchi Design of Experiment (DoE)}

In order to evaluate the influence of formulation parameters and minimize the number of experiments, Taguchi DoE being appropriate to study large number of factors, was employed through Minitab ${ }^{\circledR}$ 16 Statistical Software. Seven factors, namely, polymer MW, organic solvent, internal aqueous phase concentration and volume, sonication time, stirrer speed and external aqueous phase concentration were evaluated by constructing and using L18 orthogonal array design with 1 factor, MW, at 2 levels and remaining 6 factors at 3 levels (Table I).

The design was applied to identify the significant factors that would affect the size of PGA-coPDL NPs. Optimum conditions were indicated by high signal-to-noise $(\mathrm{S} / \mathrm{N})$ ratios, where signal factor (S) is the outcome, the particle size, and noise factors $(\mathrm{N})$ are parameters such as humidity, temperature, experience of the experimenter etc. A greater $\mathrm{S} / \mathrm{N}$ ratio corresponds to minimum variance of the outcome, the particle size i.e. a better performance. In other words, the experimental parameter having the least variability is the optimum condition (30). The optimization of size was carried out using the Taguchi's 'smaller-is-better' criterion i.e. to get the outcome, the particle size, to an ideal target of zero or as small as possible.

Table I Taguchi’s Experimental Design L18 for Producing PGA-co-PDL Nanoparticles

\begin{tabular}{|c|c|c|c|c|}
\hline Levels & Units & 1 & 2 & 3 \\
\hline A - MW of Polymer & $\mathrm{KDa}$ & 14.7 & 24.0 & - \\
\hline B Org Sol (DCM) & $\mathrm{ml}$ & 1 & 1.5 & 2 \\
\hline C- Aq. Vol (PVA) & $\mathrm{ml}$ & 3 & 4 & 5 \\
\hline$D-1^{\text {th }} \mathrm{Aq} \cdot \operatorname{Conc}$ (PVA) & $\% w /$ & 2.5 & 5 & 10 \\
\hline E-Sonication Time & $\min$ & I & 2 & 5 \\
\hline F-Stirrer Speed & RPM & 400 & 500 & 600 \\
\hline$G-2^{\text {rd }} \mathrm{Aq}$. Conc (PVA) & $\% w /$ & 0.5 & 0.75 & 1 \\
\hline
\end{tabular}

\section{Protein Adsorption}

NP suspension (equivalent to $10 \mathrm{mg}$ i.e. $1.25 \mathrm{ml}$ of suspension) was centrifuged (78,000 $\mathrm{g}, 40 \mathrm{~min}, 4^{\circ} \mathrm{C}$ ) and the resultant pellet was resuspended in vials containing $4 \mathrm{ml}$ of BSA (or FITC-BSA for characterization of protein adsorption onto the surface of PGA-co-PDL via confocal microscopy), for 1 h, at different ratios of 100: 4, 100: 10 and 100: 20 (NP: BSA) corresponding to 100, 250 and 500 $\mu \mathrm{g} / \mathrm{ml}$ BSA concentrations, respectively. The resulting suspension (for 100: 20) was left rotating for $30 \mathrm{~min}, 1,2$ and $24 \mathrm{~h}$ at 20 RPM on a HulaMixer ${ }^{\mathrm{TM}}$ Sample Mixer (Life Technologies, Invitrogen, UK). After respective time points, the protein adsorbed NP suspensions were centrifuged and the supernatant analysed for protein content using micro BCA protein assay kit. The amount of BSA adsorbed per milligram of NPs $(n=3)$ was calculated using Eq. 1: 
Adsorption ( $\mu$ g per mg NPs)

$$
=\frac{(\text { Initial protein conc-Supernatant protein conc })}{\text { Amount of NPs }}
$$

The particle size and PDI were then characterised as mentioned in "Nanoparticle Characterization” Section.

\section{Nanoparticle Characterization}

Particle size, poly dispersity index (PDI, a number between 0 and 1 describing the homogeneity of the sample) and zeta- potential were measured by laser diffraction using a laser particle size analyser (Zetasizer Nano ZS, Malvern Instru- ments Ltd, UK). For NPs suspension, an aliquot of $100 \mu 1$ was diluted with $5 \mathrm{ml}$ of deionized water and for NP suspensions with and without BSA adsorption, $2 \mathrm{mg}$ of NPs were resuspended in $5 \mathrm{~mL}$ of deionized water, loaded into a cuvette and the measurements were recorded at $25^{\circ} \mathrm{C}(n=3)$.

\section{Nanocomposite Microparticles}

Spray-drying was employed to incorporate the NPs into nano-composite microparticles (NCMPs) using L-leu as a carrier, and at nanoparticles-to-carrier ratio of 1:1.5w/w. Blank NPs, BSA-loaded NPs or FITC-BSA-loaded NR NPs were dispersed in $20 \mathrm{ml}$ water with L-leu dissolved and spray-dried using a Büchi B-290 mini spray-dryer (Büchi Labortechnik, Flawil, Switzerland) with a nozzle atomizer, and nozzle orifice diameter of $0.7 \mathrm{~mm}$. The SD was performed at a feed rate $10 \%$, an atomizing air flow of $400 \mathrm{~L} / \mathrm{h}$, aspirator capacity of $100 \%$ and an inlet temperature of $100^{\circ} \mathrm{C}$ (outlet temperature approximately $45-47^{\circ} \mathrm{C}$ ). The dry particles (PGA-co-PDL/L-leu NCMPs) were separated from the air stream using a high-performance cyclone (Büchi Labortechnik), and the dry particles were collected and stored in desiccator until further use.

\section{NanocompositeMicroparticles Characterization \\ Yield}

The dry powder yield was determined as the difference in the weight of the sample vial before and after product collection. The weight difference was compared to the initial total dry mass and the yield in $\%(w / w)$ was calculated $(n=3)$.

\section{Particle Size and Morphology}

To confirm the recovery of NPs from NCMPs with an appro- priate size range for cellular uptake, particle size and PDI of NPs following re-dispersion of blank and loaded NCMPs in water were measured. The measurements were recorded as mentioned in "Nanoparticle Characterization" Section, where 5 mg of NCMPs were dispersed in $2 \mathrm{ml}$ of deionized water then loaded into a cuvette and the measurements were recorded at $25^{\circ} \mathrm{C}(n=3)$.

Spray dried PGA-co-PDL/L-Leu NCMPs samples were mounted on aluminium stubs (pin stubs, $13 \mathrm{~mm}$ ) layered with a sticky conductive carbon tab and coated with palladium (10-15 nm) using 
a sputter coater (EmiTech K 550X Gold Sputter Coater, $25 \mathrm{~mA}$ for $3 \mathrm{~min}$ ). The particles were then visualized using scanning electron microscopy (FEI Quanta ${ }^{\mathrm{TM}} 200$ ESEM, Holland).

\section{Confocal Laser Scanning Microscopy}

FITC-BSA-loaded NR NPs spray-dried into NCMPs were observed under confocal microscope to visualise the adsorption of BSA onto the NPs. Briefly, a Zeiss 510 Meta laser scanning microscope mounted on a Axiovert 200 M BP computer-controlled inverted microscope was used to obtain the confocal images. A few milligrams of spray-dried NCMPs were placed in a single well of 8-well chambered (Fisher Scientific, UK) and imaged by excitation at a wavelength of $488 \mathrm{~nm}$ (green channel for FITC-BSA), $543 \mathrm{~nm}$ (red channel for Nile Red NPs) and a Plan Neofluar 63×/0.30 numerical aperture (NA) objective lens. Image analysis was carried out using the Zeiss LSM software.

\section{Protein Quantification by HPLC}

An HPLC method was developed to quantify the amount of BSA present in NCMPs. The chromatographic conditions were as follows: HPLC system Agilent 1100 series (Santa Clara, CA, USA) equipped with a column (Aeris $3.6 \mu \mathrm{m} \mathrm{C4} \mathrm{200A} \mathrm{Wide} \mathrm{Pore} 4.6 \mathrm{~mm}$ i.d. $\times 150 \mathrm{~mm}$ length), security cartridge of the same material (Phenomenex, UK) and soft- ware for data processing; mobile phase was composed of (A) $0.1 \%$ TFA in water and (B) $0.1 \%$ TFA in acetonitrile with a gradient flow of $\mathrm{A} / \mathrm{B}$ from $80: 20$ to 35:65 in $25 \mathrm{~min}$, post-time $6 \mathrm{~min}$; flow rate of $0.8 \mathrm{ml} / \mathrm{min}$; injection volume of $100 \mu \mathrm{l}$; run temperature $40^{\circ} \mathrm{C}$; UV detection at $214 \mathrm{~nm}$ and BSA retention time of $14.4 \mathrm{~min}$. BSA calibration curve was prepared by accurate dilution of a previously prepared stock solution $(1 \mathrm{mg} / \mathrm{ml})$ in HPLC water and PBS (pH 7.4) to obtain the following concentrations: 0.5, 1, 2.5, 5, 10, 25, 50, 100 and $200 \mu \mathrm{g} / \mathrm{ml}$ of BSA $(n=9, R 2=0.999)$. All solutions used in the process were filtered using $0.45 \mu \mathrm{m}$ filters prior to use. Limit of Detection (LOD) in water- $1.98 \mu \mathrm{g} / \mathrm{ml}$, PBS $-1.48 \mu \mathrm{g} / \mathrm{ml}$ and Limit of Quantification (LOQ) in water-3.24 $\mu \mathrm{g} / \mathrm{ml}$, PBS-3.20 $\mu \mathrm{g} / \mathrm{ml}$.

\section{In Vitro Release Studies}

BSA adsorbed PGA-co-PDL/L-leu NCMPs (20 mg) were transferred into Eppendorf's and dispersed in $2 \mathrm{ml}$ of PBS, pH 7.4. The samples were incubated at $37^{\circ} \mathrm{C}$ and left rotating for $48 \mathrm{~h}$ at $20 \mathrm{RPM}$ on a HulaMixer ${ }^{\mathrm{TM}}$ Sample Mixer (Life Technologies, Invitrogen, UK). At pre-determined time intervals up to $48 \mathrm{~h}$, the samples were centrifuged (accuSpin Micro 17, Fisher Scientific, UK) at 17,000 g for $30 \mathrm{~min}$ and $1 \mathrm{ml}$ of the supernatant removed and replaced with fresh medium. The supernatant was analysed using the HPLC method as mentioned above. Each experiment was repeated in triplicate and the result was the mean value of three different samples $(n=3)$. The percentage cumulative BSA released was calculated using Eq. 2:

$$
\% \text { Cumulative BSA released }=\frac{\text { Cumulative BSA released }}{\text { BSA loaded }} \times 100
$$

\section{Sodium Dodecyl Sulfate-Polyacrylamide Gel Electrophoresis (SDS-PAGE)}

The primary structure of BSA released from the NCMPs after SD was determined by SDS-PAGE. SDSPAGE was per- formed on CVS10D omniPAGE vertical gel electrophoresis system (Geneflow Limited, UK) with 9\% stacking gel pre- pared using ProtoGel stacking buffer (Geneflow Limited, UK) containing $0.4 \%$ of SDS. Protein molecular weight markers in the range 10-220 KDa (Geneflow 
Limited, UK) and BSA were used as control. The protein loading buffer blue (2X) (0.5 M Tris-HCl (pH 6.8), 4.4\% (w/v) SDS, 20\% ( $v / v)$ Glycerol, 2\% ( $v / v)$ 2- mercaptoethanol and bromphenolblue in distilled/deionised water) was added to the samples in 1:1 $(v / v)$ buffer-to-sample ratio. After loading the samples (25 $\mu$ l sample per well), the gel was run for approximately $2.5 \mathrm{~h}$ at a voltage of $100 \mathrm{~V}$ with Tris-Glycine-SDS PAGE buffer (10X) (Geneflow Limited, UK) containing 0.25 M Tris base, $1.92 \mathrm{M}$ glycine and $1 \%(w / v)$ SDS. The gel was stained with colloidal coomassie blue and then destained in distilled water overnight. An image of the gel was scanned on a gel scanner (GS-700 Imaging Densitometer, Bio-Rad) equipped with Quantity One software.

\section{Circular Dichroism (CD)}

The secondary structure of standard BSA (control), BSA supernatant (after $1 \mathrm{~h}$ adsorption followed by centrifugation) and BSA released from NPs after $48 \mathrm{~h}$ was determined by measuring circular dichroism spectra. All CD experiments were performed using a J-815 spectropolarmeter (Jasco, UK) at $20^{\circ} \mathrm{C}$ as previously described (31). Five scans per sample using a $10 \mathrm{~mm}$ path-length cell were performed over a wavelength range 260 to $180 \mathrm{~nm}$ at a data pitch of $0.5 \mathrm{~nm}$, band width of $1 \mathrm{~nm}$ and a scan speed $50 \mathrm{~nm}$ min-1. Far-UV CD spectra were collated for standard BSA, supernatant BSA in HPLC grade water, BSA released in PBS for $48 \mathrm{~h}$. For all spectra, the baseline acquired in the absence of sample was subtracted (32). The secondary structure of the samples was estimated using the CDSSTR method (33) from the DichroWeb server (33-35).

\section{Activity}

The activity of BSA was investigated using 4-nitrophenyl acetate esterase substrate (NPA, Sigma Aldrich, UK) as described by Abbate et al. (36). Briefly, $1.2 \mathrm{ml}$ of released BSA sample (50 $\mu \mathrm{g} / \mathrm{ml})$ in PBS was added to freshly prepared NPA solution ( $15 \mu 1$ of a $5 \mathrm{mM}$ solution in ACN) and incubated for $1 \mathrm{~h}$ using HulaMixer ${ }^{\mathrm{TM}}$ Sample Mixer. Thereafter, the solution was transferred to a plastic cuvette and absorbance measured at $405 \mathrm{~nm}$. For positive control, standard BSA (50 $\mu \mathrm{g} / \mathrm{ml}$ ) was treated exactly the same as released sample whereas for negative control, PBS buffer alone was treated as sample. The relative residual esterolytic activity of the samples was calculated as the ratio of absorbance between the released BSA/standard BSA, with the esterolytic activity obtained for standard BSA considered to be $100 \%$.

\section{In Vitro Aerosolization Studies}

The Next Generation Impactor (NGI) was employed to assess the aerosol performance of spray-dried NCMPs. The BSA adsorbed NCMPs were weighed (4 capsules each corresponding to $12.5 \mathrm{mg}$ spraydried, powder equivalent to $5 \mathrm{mg}$ of NPs) and manually loaded into the hydroxypropyl methylcellulose, HPMC, capsule (size 3), and placed in a Cyclohaler ${ }^{\circledR}$ (Teva pharma). The samples were drawn through the induction port into the NGI using a pump (Copley Scientific, Nottingham, UK) operated at a flow rate of $60 \mathrm{~L} / \mathrm{min}$ for $4 \mathrm{~s}$. The plates were coated with $1 \%$ tween 80 : acetone solution and samples collected using a known volume of distilled water, and left on a roller-shaker for $48 \mathrm{~h}$ for the BSA to be released from NCMPs. The samples were centrifuged using an ultracentrifuge (as mentioned in "Preparation of Nanoparticles" Section) and the supernatants analysed using HPLC method as mentioned above to determine the amount of BSA deposited. The Fine Particle Fraction (FPF, \%) was determined as the fraction of emitted dose deposited in the NGI with $d_{a e}<4.46 \mu \mathrm{m}$, the mass median 
aerodynamic diameter (MMAD) was calculated from log-probability analysis, and the fine particle dose (FPD) was expressed as the mass of drug deposited in the NGI with $\mathrm{d}_{\mathrm{a}}<4.46 \mu \mathrm{m}(n=3)$.

\section{Cell Viability Study}

The in vitro cytotoxicity of the empty PGA-co-PDL/L- leu NCMPs was evaluated using the MTT assay. The adenocarcinomic human alveolar basal epithelial cell line, A549 (passage no. 32) or 16HBE14o- cells (passage no. 32) were seeded in $100 \mu \mathrm{l}\left(2.5 \times 10^{5}\right.$ cells/ml) of RPMI-1640 medium supplemented with $10 \%$ foetal calf serum/1\% Antibiotic/Antimycotic solution (complete medium) in 96-well plates and placed in an incubator at $37^{\circ} \mathrm{C}$ for $24 \mathrm{~h}$ supplemented with $5 \% \mathrm{CO} 2$. Then, $100 \mu \mathrm{l}$ of freshly prepared NCMP dispersions in complete medium were added to the wells to an appropriate concentration $(0-2.5 \mathrm{mg} / \mathrm{ml})(n=3)$, and 10\% dimethyl sulfoxide (DMSO) as a positive control. The formulations were assayed for toxicity over $24 \mathrm{~h}$ of incubation, followed by the addition of $40 \mu \mathrm{l}$ of a $5 \mathrm{mg} / \mathrm{ml}$ MTT solution in PBS to each well. After $2 \mathrm{~h}$ of incubation at $37^{\circ} \mathrm{C}$, the culture medium was gently removed and replaced by $100 \mu$ of dimethyl sulfoxide in order to dissolve the formazan crystals. The absorbance of the solubilised dye, which correlates with the number of living cells, was measured at $570 \mathrm{~nm}$ using a plate reader (Molecular Devices, SpectraMAX 190). The percentage of viable cells in each well was calculated as the absorbance ratio between nanoparticle-treated and untreated control cells.

\section{Statistical Analysis}

All statistical analysis was performed using Minitab® 16 Statistical Software. One-way analysis of variance (ANOVA) using Minitab® 16 Statistical Software with the Tukey’s comparison was employed for comparing the formulations with each other. Statistically significant differences were assumed when $p<0.05$. All values are expressed as their mean \pm standard deviation. 


\section{RESULTS}

\section{Polymer Synthesis}

The synthesized PGA-co-PDL co-polymer (monomer ratio, 1:1:1) was a white powder with a molecular weight of 14.7,24.0 KDa for $6 \mathrm{~h}, 24 \mathrm{~h}$ as determined by the GPC. The integration pattern of the copolymer was confirmed by 1H- NMR spectra, $(\delta \mathrm{H} \mathrm{CDCl3}, 300 \mathrm{MHz}): 1.34(\mathrm{~s}, 22 \mathrm{H}, \mathrm{H}-\mathrm{g}), 1.65(\mathrm{~m}, 8 \mathrm{H}$, H-e, e', h), 2.32 (m, 6 H, H-d, d', i), 4.05 (q)-4.18 (m) (6 H, H-a, b, c, f), 5.2 (s, H, H-j).

\section{Taguchi Design of Experiment (DoE)}

The Taguchi design was applied in this study to identify the significant factors that would influence the size of PGA-co- PDL NPs. Considering seven factors (1 factor at 2 levels and 6 factors at 3 levels) to be investigated, non-usage of an experimental design would have resulted in $2 * 3^{6}=1,458$ individual experiments which would be an arduous task and inefficient.

The Taguchi L18 orthogonal array design resulted in 18 runs to be performed to yield the optimum conditions for each factor in achieving the smallest PGA-co-PDL NP size. Table II illustrates the structure of the L18 orthogonal array, the corresponding results and S/N ratios. The results obtained from 18 runs indicated particle sizes ranging from $138.7 \pm 6.4 \mathrm{~nm}$ (run 3) to $459.4 \pm 69.5 \mathrm{~nm}$ (run 11). Figure 1 shows the mean $\mathrm{S} / \mathrm{N}$ graph of the particle size for each parameter level. The parameter with the largest range and corresponding rank (indicates the relative importance compared to other parameters) was considered as the critical factor affecting that particle size.

Analysis of the particle sizes of 18 runs using the Taguchi's 'smaller-is-better' criterion in Minitab® 16 Statistical Software, the optimum conditions inferred from the range, rank and the S/N response graph were A1B3C3D3E2F2G2. The optimum formulation made using these conditions yielded NPs with a size of $128.50 \pm 6.57 \mathrm{~nm}$ lower than the minimum size of $138.7 \pm 6.4 \mathrm{~nm}$ obtained using run 3 , PDI of $0.07 \pm$ 0.03 and zeta-potential of $-10.2 \pm 3.75 \mathrm{mV}$.

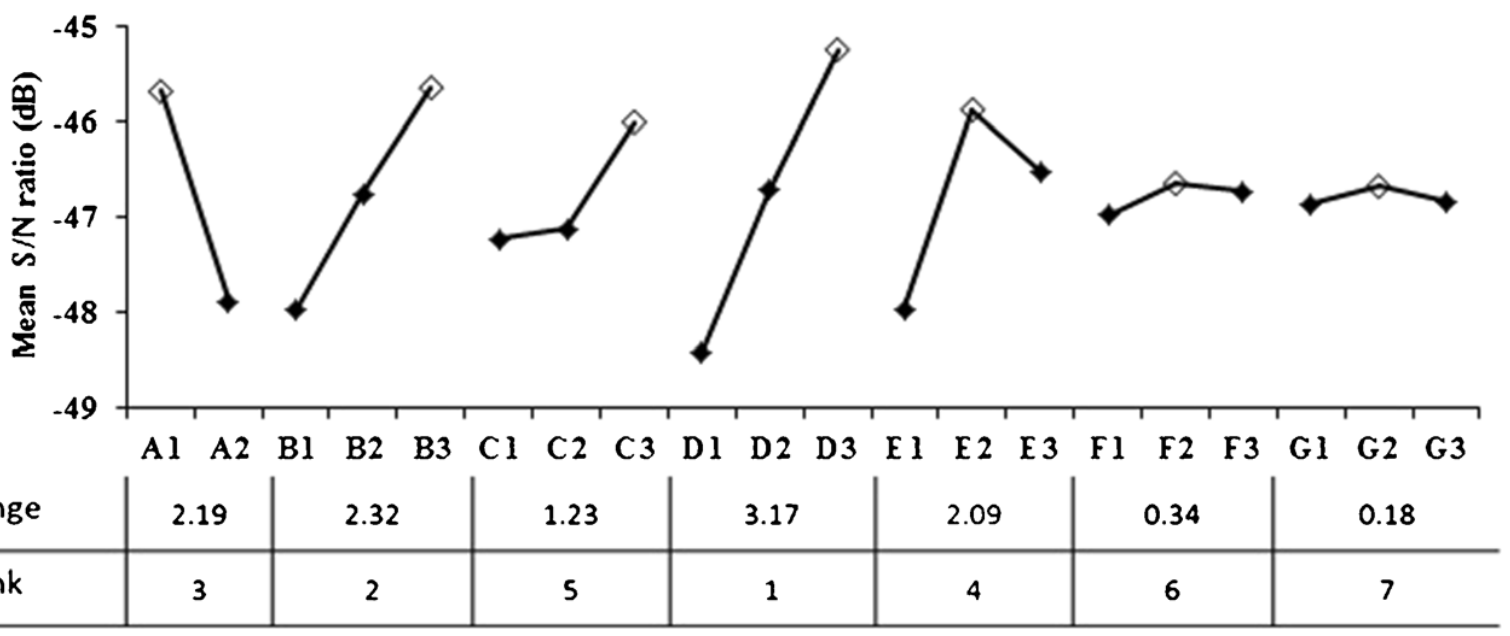

Parameter Levels

Fig. 1 Mean S/N graph for particle size response. Letters (A-E) denote the experimental parameters and numeric values denote the parameter levels (white diamond indicates maximum $\mathrm{S} / \mathrm{N}$ value) (Mean $\pm \mathrm{SD}, \mathrm{n}=6$ ); Note: $\mathrm{A}-\mathrm{MW}$ of Polymer, $\mathrm{B}-\mathrm{Org}$ Sol (DCM), C-Aq. Vol (PVA), D-1st Aq. conc (PVA), E- Sonication time, F-Stirrer Speed and G-2nd Aq. conc (PVA). 
Table II Structure of Taguchi's $\mathrm{L}_{18}$ Orthogonal Array, Corresponding Particle Size and $S / N$ Ratios (Mean $\pm S D, n=6$ )

\begin{tabular}{|c|c|c|c|c|c|c|c|c|c|c|}
\hline \multirow[t]{2}{*}{ Runs } & \multicolumn{7}{|c|}{ Parameters } & \multirow[t]{2}{*}{ ParticleSize(nm) } & \multirow[t]{2}{*}{ PDI } & \multirow[t]{2}{*}{ S/ NRatio (dB) } \\
\hline & A & $B$ & $\mathrm{C}$ & $\mathrm{D}$ & $E$ & $\mathrm{~F}$ & G & & & \\
\hline Run 1 & 1 & 1 & 1 & 1 & 1 & 1 & 1 & $315.5 \pm 6.90$ & $0.151 \pm 0.05$ & -49.979 \\
\hline Run 2 & 1 & 1 & 2 & 2 & 2 & 2 & 2 & $186.5 \pm 4.30$ & $0.097 \pm 0.03$ & -45.412 \\
\hline Run 3 & 1 & 1 & 3 & 3 & 3 & 3 & 3 & $138.7 \pm 6.40$ & $0.093 \pm 0.01$ & -42.843 \\
\hline Run 4 & 1 & 2 & 1 & 1 & 2 & 2 & 3 & $210.1 \pm 18.7$ & $0.116 \pm 0.04$ & -46.449 \\
\hline Run 5 & 1 & 2 & 2 & 2 & 3 & 3 & 1 & $208.7 \pm 49.9$ & $0.123 \pm 0.06$ & -46.389 \\
\hline Run 6 & 1 & 2 & 3 & 3 & 1 & 1 & 2 & $182.0 \pm 3.20$ & $0.075 \pm 0.04$ & -45.199 \\
\hline Run 7 & 1 & 3 & 1 & 2 & 1 & 3 & 2 & $192.9 \pm 9.30$ & $0.077 \pm 0.04$ & -45.705 \\
\hline Run 8 & 1 & 3 & 2 & 3 & 2 & 1 & 3 & 149. $3 \pm 2.50$ & $0.075 \pm 0.01$ & -43.481 \\
\hline Run 9 & 1 & 3 & 3 & 1 & 3 & 2 & 1 & $192.9 \pm 23.0$ & $0.050 \pm 0.03$ & -45.704 \\
\hline Run 10 & 2 & 1 & 1 & 3 & 3 & 2 & 2 & $269.1 \pm 68.9$ & $0.205 \pm 0.04$ & -48.598 \\
\hline Run 11 & 2 & 1 & 2 & 1 & 1 & 3 & 3 & $459.4 \pm 69.5$ & $0.233 \pm 0.02$ & -53.243 \\
\hline Run 12 & 2 & 1 & 3 & 2 & 2 & 1 & 1 & $242.5 \pm 19.1$ & $0.188 \pm 0.06$ & -47.694 \\
\hline Run 13 & 2 & 2 & 1 & 2 & 3 & 1 & 3 & $253.2 \pm 47.3$ & $0.155 \pm 0.10$ & -48.069 \\
\hline Run 14 & 2 & 2 & 2 & 3 & 1 & 2 & 1 & $217.3 \pm 18.9$ & $0.116 \pm 0.01$ & -46.742 \\
\hline Run 15 & 2 & 2 & 3 & 1 & 2 & 3 & 2 & $240.5 \pm 35.1$ & $0.133 \pm 0.05$ & -47.622 \\
\hline Run 16 & 2 & 3 & 1 & 3 & 2 & 3 & 1 & $169.3 \pm 7.60$ & $0.144 \pm 0.04$ & -44.573 \\
\hline Run 17 & 2 & 3 & 2 & 1 & 3 & 1 & 2 & $235.9 \pm 29.6$ & $0.119 \pm 0.08$ & -47.453 \\
\hline Run 18 & 2 & 3 & 3 & 2 & 1 & 2 & 3 & $221.7 \pm 11.0$ & $0.150 \pm 0.04$ & -46.915 \\
\hline
\end{tabular}

A-MWof Polymer, B-Org Sol (DCM), C—Aq. Vol (PVA), D—-1st Aq. conc (PVA), E-Sonicationtime, F-Stirrer Speed and G—2nd Aq. conc (PVA)

\section{Protein Adsorption}

Figure 2a shows the amount of BSA adsorbed per mg of NPs for different concentrations of BSA loaded. The average ad- sorption of BSA, $\mu \mathrm{g}$ per mg of NPs, increased significantly from 100: 4 (NP: BSA) loading concentration (4.75 \pm 0.39$), 100: 10(6.59 \pm 1.28)$ to $100: 20(10.23 \pm 1.87)(\mathrm{p}<0.05$, ANOVA/Tukey's comparison). Figure $2 \mathrm{~b}$ shows the amount of BSA adsorbed in $\mu \mathrm{g}$ per mg of NPs at different time points for 100: 20 (NP: BSA) loading concentration. The average adsorption increased significantly from 30 min $(1.84 \pm 0.82)$ to $1 \mathrm{~h}(10.23 \pm 1.87)(\mathrm{p}<0.05$, ANOVA/Tukey’s comparison) with no significant difference beyond $1 \mathrm{~h}$ compared to that of $2 \mathrm{~h}(8.76 \pm 0.34)$ and $24 \mathrm{~h}(8.95 \pm$ 0.39) ( $\mathrm{p}>0.05$, ANOVA/Tukey's comparison) indicating maximum adsorption at $1 \mathrm{~h}$. Table III lists the particle size and PDI of PGA-co-PDL NPs with and without BSA adsorption. As seen, there is a significant increase ( $<<0.05$, ANOVA/Tukey's comparison) in size which is attributed to the adsorption of BSA onto NPs as confirmed using confocal microscopy ("Confocal Laser Scanning Microscopy" Section).

(a)

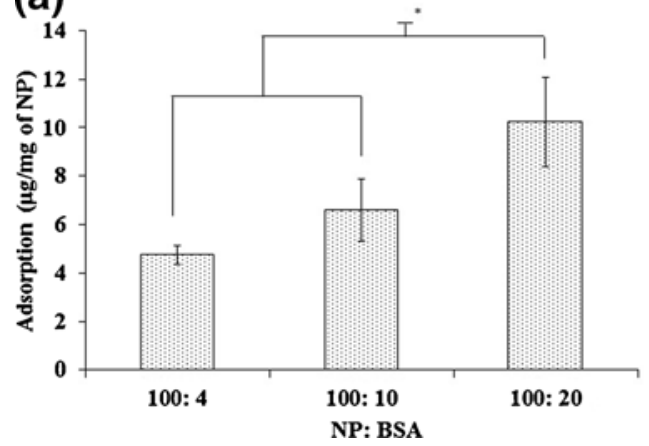

(b)

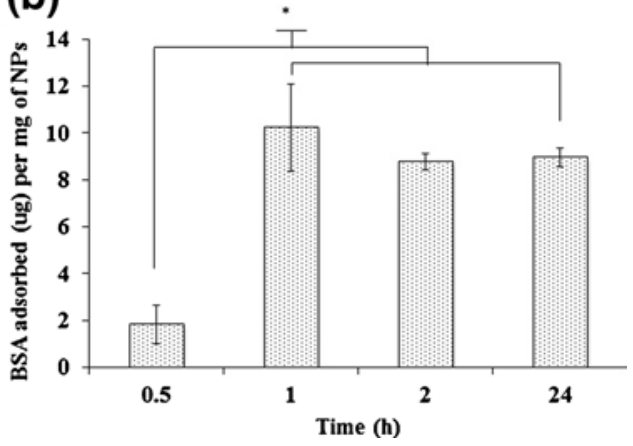

Fig. 2 Amount of BSA adsorbed per mg of NPsat different (a) BSA loading concentrations (NP: BSA) and (b) time points for 100: 20 (NP: BSA) BSA loading concentration, *is $p<0.05$, ANOVA/ Tukey's comparison (Mean $\pm S D, n=3$ ). 
Table III Particle Size and PDI of PGA-co-PDL Nanoparticles Without and with BSA Adsorption

\begin{tabular}{lrrr}
\hline & NP suspension & Without BSA adsorption & With BSA adsorption \\
\hline Particle Size $(\mathrm{nm})$ & $128.50 \pm 6.57^{\mathrm{a}}$ & $203.9 \pm 2.55^{\mathrm{b}^{*}}$ & $299.03 \pm 32.02^{\mathrm{c}^{*}}$ \\
$\mathrm{PDI}$ & $0.070 \pm 0.030$ & $0.205 \pm 0.007$ & $0.322 \pm 0.060$ \\
\hline
\end{tabular}

* $\mathrm{p}<0.05$, ANOVA/Tukey's comparison

a NPs characterised immediately after preparation without centrifugation, ${ }^{\mathrm{b}}$ NPs characterised after centrifugation but without adsorption of BSA, ${ }^{\mathrm{C}} \mathrm{NPs}$ characterised after centrifugation and BSA adsorption.

\section{Nanocomposite Microparticles Characterization}

\section{Yield}

A reasonable yield of SD, $40.36 \pm 1.80 \%$ for the empty PGA- co-PDL NCMPs and $42.35 \pm 3.17 \%$ for the BSA adsorbed PGA-co-PDL/L-leu NCMPs was obtained.

\section{Particle Size and Morphology}

The size of NPs after recovery from spray-dried blank NCMPs in water was $210.03 \pm 15.57 \mathrm{~nm}$ and PDI $0.355 \pm 0.067$ and for that of BSA loaded NCMPs was 282.46 $\pm 2.17 \mathrm{~nm}$ and PDI 0.36 \pm 0.008 , which is in the range of 200 to $500 \mathrm{~nm}$ for uptake by dendritic cells (DCs) (16-18). The shape and surface texture of NCMPs were investigated using scanning electron microscopy (Fig. 3). Photomicrographs of NCMPs showed irregular and corrugated microparticles.
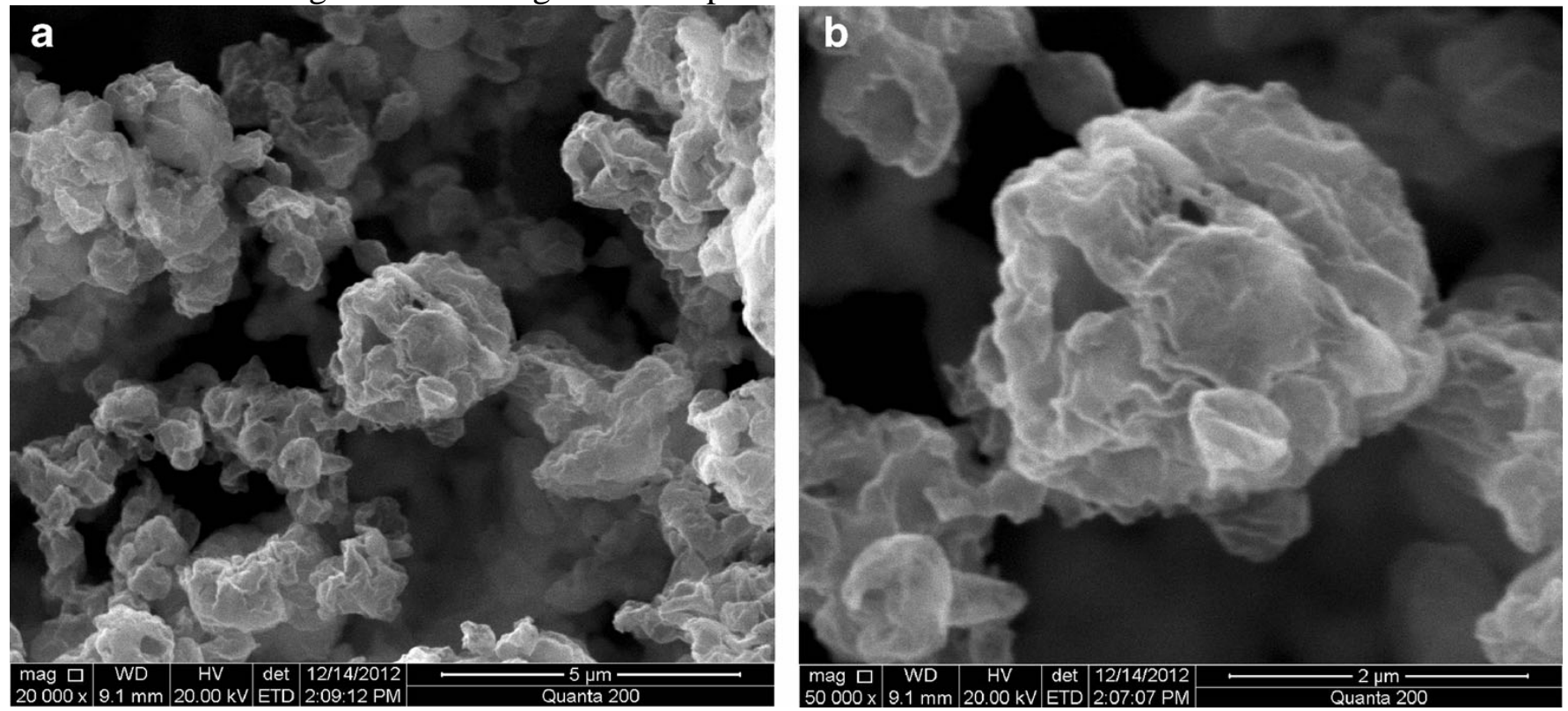

Fig. 3 SEM pictures of PGA-co-PDL/L-Leu Nanocomposite Microparticles (a) $5 \mu \mathrm{m}$ and (b)2 $\mu \mathrm{m}$.

\section{Confocal Laser Scanning Microscopy}

CLSM was used to observe the interaction of BSA with NPs. The microscopic images in Fig. 4a (split view) and 4b (orthogonal view) shows the spray-dried NCMPs containing the fluorescent NPs (red, labelled using NR dye) adsorbed with FITC-BSA (green). The image shows that FITC-BSA was evidently only present where the NPs were present, indicating their association. Moreover, the increase in size observed after adsorption also confirms the adsorption of BSA onto PGA-co-PDL NPs (Table 
III).
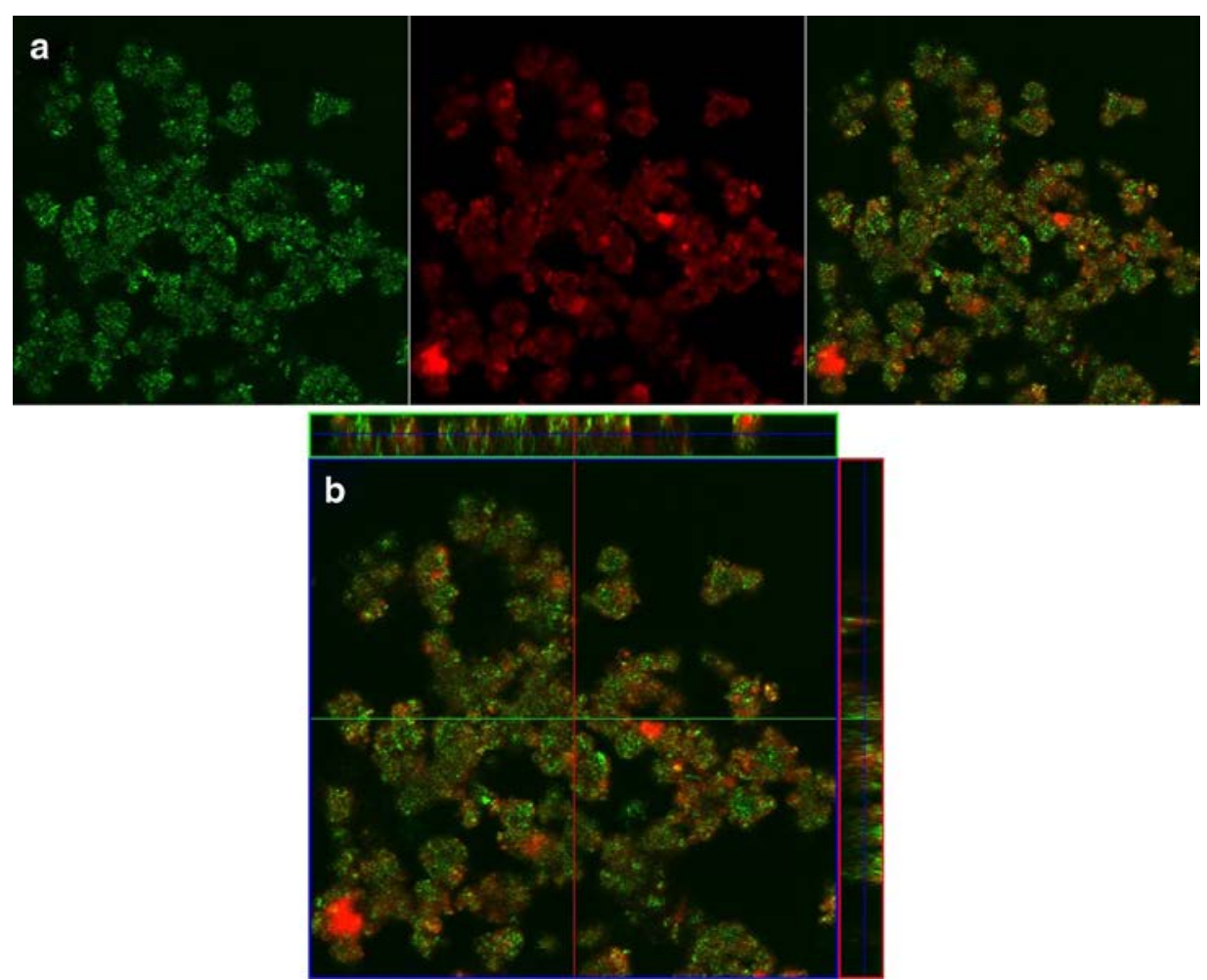

Fig. 4 Confocal microscopic image of spray-dried microparticles containing the fluorescent nanoparticles (red, labelled using nile red dye) adsorbed with FITC-BSA (green) (a) Split view and (b) Orthogonal view.

\section{In Vitro Release Studies}

In vitro release studies were performed on NCMPs and reported as cumulative percentage BSA released over time (Fig. 5). An initial burst release of 30.15 $\pm 2.33 \%$ (BSA) was observed followed by continuous release up to $5 \mathrm{~h}$, with BSA release of $86.07 \pm 0.95 \%$. After this time period, a slow continuous release of BSA was observed with release of $95.15 \pm 1.08 \%$ over $48 \mathrm{~h}$, indicating an excellent release profile for the PGA-co- PDL/L-leu NCMPs.

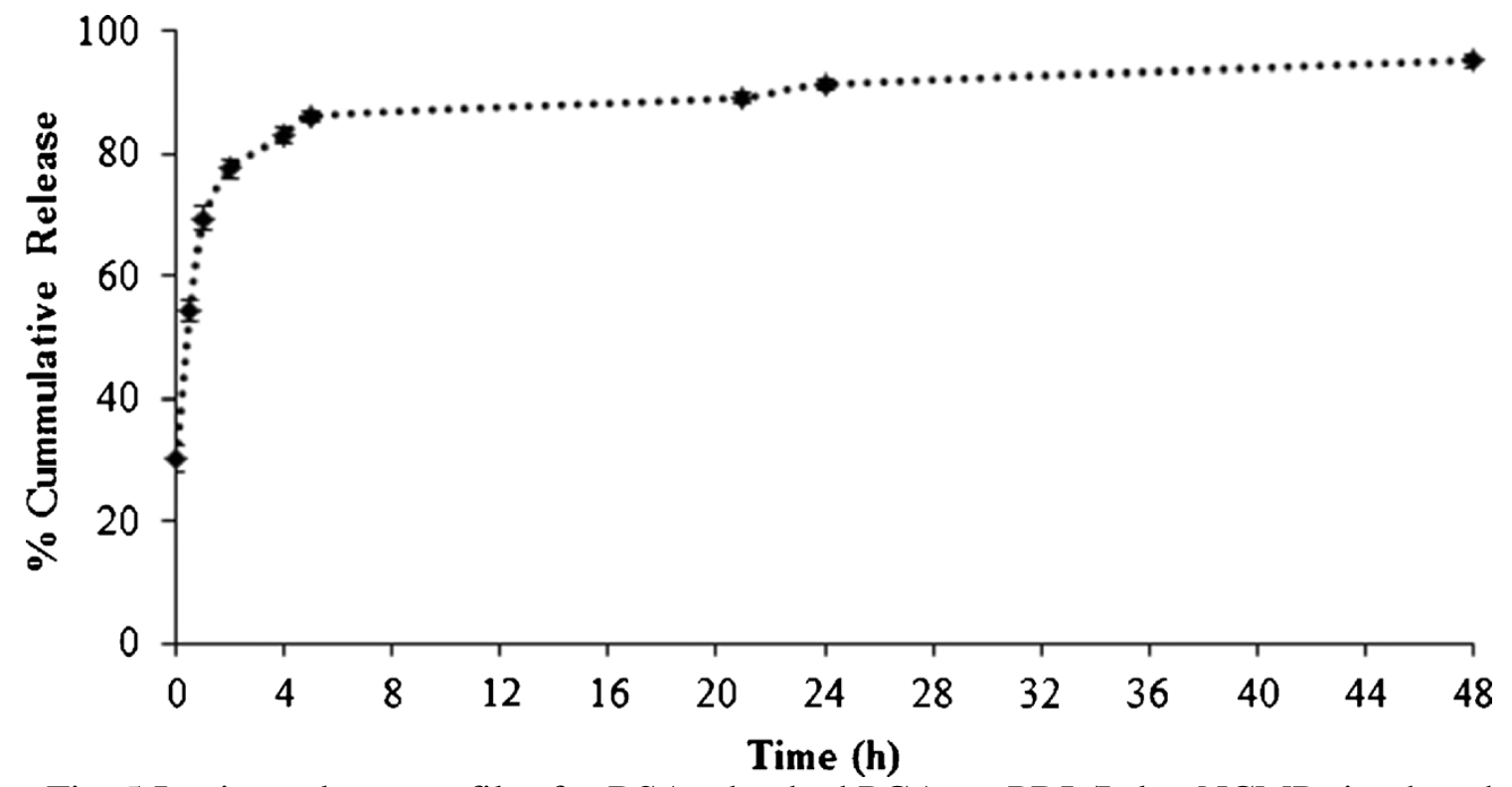

Fig. 5 In vitro release profiles for BSA adsorbed PGA-co-PDL/L-leu NCMPs in phosphate buffer 
saline, $\mathrm{pH} 7.4($ Mean \pm SD, $\mathrm{n}=3)$.

\section{Protein Stability (SDS-PAGE and CD) and Activity}

The primary structure of BSA released from the NCMPs was investigated using SDS-PAGE analysis. Figure 6 reveals identical bands for the standard BSA and desorbed BSA from NCMPs without any newly noticeable bands of high and low molecular BSA.

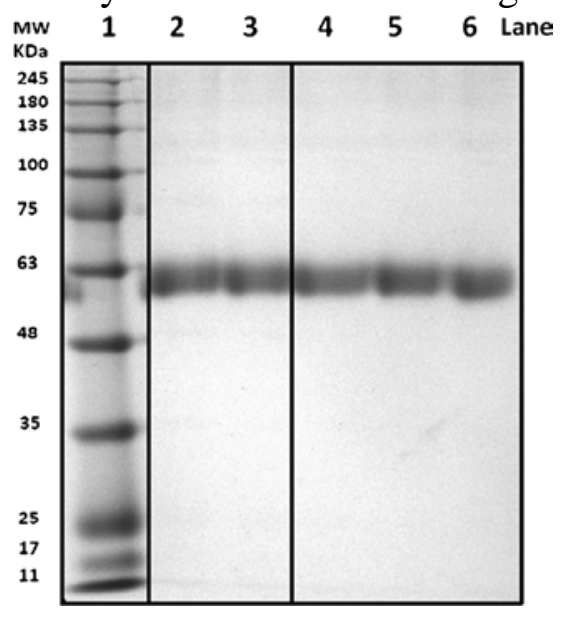

Fig. 6 SDS-PAGE of Lane 1: molecular weight standards, broad range (Bio-Rad Laboratories, Hercules CA, USA), Lane 2, 3: BSA standards, Lane 4, 5, 6: Desorbed BSA from PGA-co-PDL/L-leu NCMPs after $24 \mathrm{~h}$.

The secondary structure analysis was performed using CD spectral data. Figure 7a and b shows the structure of standard BSA, BSA supernatant and BSA released. In Fig 7a, the CD spectra show minima at 221-222 and 209-210 nm and maximum at about $195 \mathrm{~nm}$ for both samples, which is characteriistic of $\alpha$-helical structure. Further structural analysis showed that the predominant structure of the protein was helical displaying 51 and 62.5\% helicity respectively (Table IV). Moreover, the experimental data obtained for the standard BSA are in good agreement with previous reports (37). Figure 7b shows that BSA released displayed double minima at 208 and $222 \mathrm{~nm}$ and further spectra analysis indicated this sample adopted a reduced level helical conformation (circa 36\% helical) (Table IV). Comparing the CD results of BSA released with that of standard BSA, the content of $\alpha$-helix decreases by $15 \%$, the $\beta$-sheet content increases by $8.9 \%$, the turns content increases by $1 \%$, and the random coils' content increases by $3 \%$, respectively.

The residual esterolytic activity of the released BSA sample was calculated to be $77.73 \pm 3.19 \%$ relative to standard BSA. 


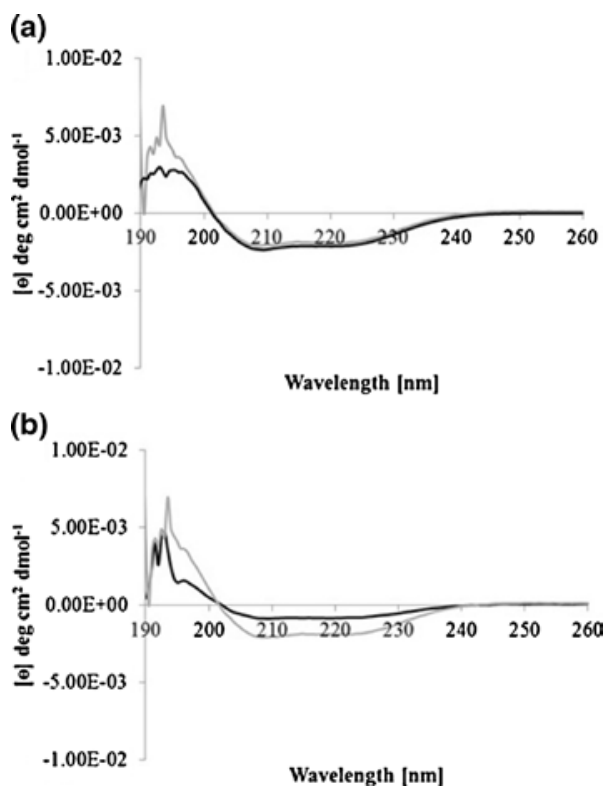

Fig. 7 CD spectra of (a) standard BSA (grey) and supernatant BSA (black) and (b) standard BSA (grey) and BSA released (black).

Table IV The Percentages of the Secondary Structures of Standard, Supernatant and Released BSA Samples

\begin{tabular}{lrllc}
\hline Sample & Helix & Strand & Turns & Unordered \\
\hline Standard BSA & $51 \pm 0.007$ & $21.1 \pm 0.07$ & $6.0 \pm 0.01$ & $18 \pm 0.007$ \\
Supernatant BSA & $62.5 \pm 0.035$ & $22.0 \pm 0.021$ & $5.5 \pm 0.05$ & $9.5 \pm 0.06$ \\
Released BSA & $36.0 \pm 0$ & $30.0 \pm 0$ & $7.0 \pm 0$ & $21 \pm 0.007$ \\
\hline
\end{tabular}

The content and level of secondary structure elements in the peptide was calculated from spectral data using the DichroWeb server software as described in "Materials and Methods" Section.

\section{In Vitro Aerosolization Studies}

The deposition data obtained from spray-dried formulations displayed a FPD of 112.87 $\pm 33.64 \mu \mathrm{g}, \mathrm{FPF}$ of $76.95 \pm 5.61 \%$ and MMAD of $1.21 \pm 0.67 \mu \mathrm{m}$. This suggest that the BSA adsorbed PGA-co-PDL/L-leu NCMPs were capable of delivering efficient BSA to the lungs, and are expected to deposit the majority of the emitted dose to the bronchial-alveolar region of the lungs (3).

\section{Cell Viability Study}

The non-adsorbed PGA-co-PDL NCMPs appear to be well tolerated by both the cell lines, with a cell viability of $87.01 \pm 14.11 \%$ (A549 cell line) and 106.04 $\pm 21.14 \%$ (16HBE14o- cell line) (Fig. 8) at 1.25 $\mathrm{mg} / \mathrm{ml}$ concentration after $24 \mathrm{~h}$ exposure indicating a good toxicity profile without any significant difference in cell viability between particle loadings. This provides an indication about the feasibility of using PGA-co-PDL polymers as safe carriers for pulmonary drug delivery. 


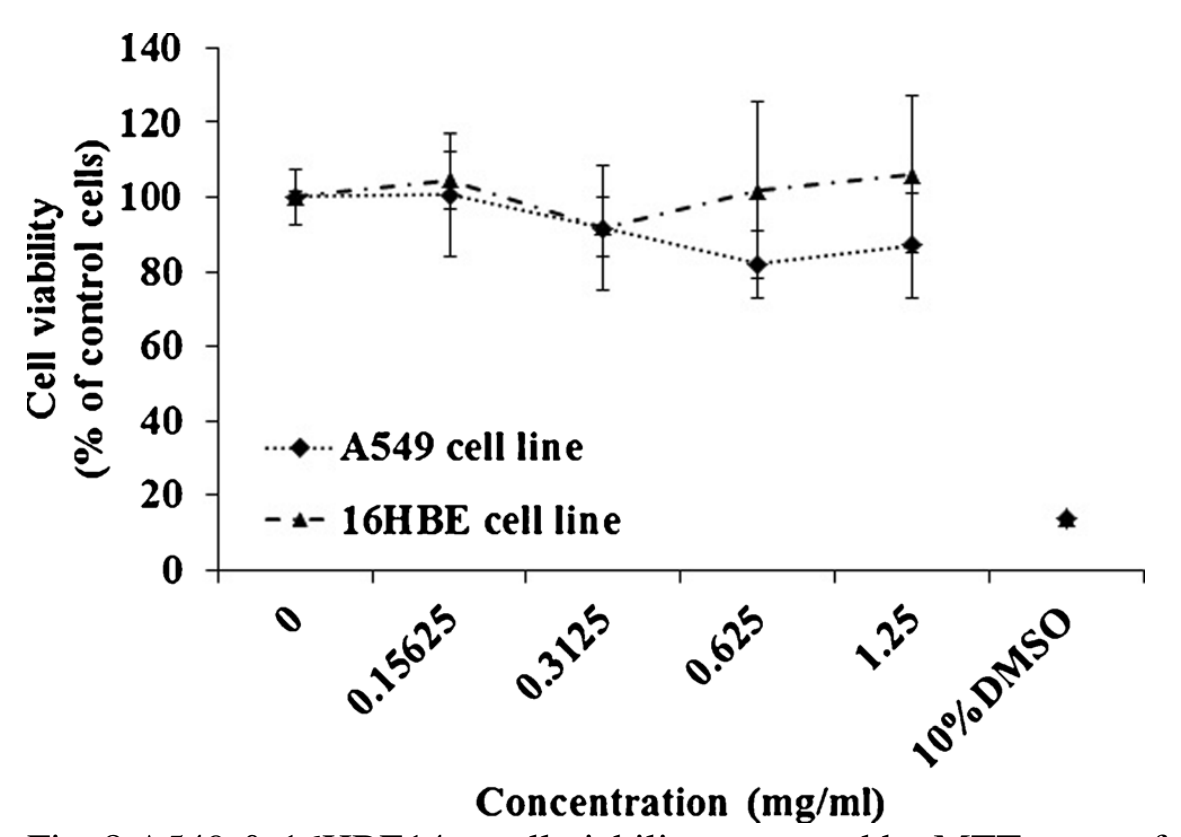

Fig. 8 A549 \& 16HBE14o- cell viability measured by MTT assay after $24 \mathrm{~h}$ exposure to PGA-co-PDL NCMPs (Mean \pm SD, $n=3$ ).

\section{DISCUSSION}

\section{Nanoparticle Preparation and Characterization}

The PGA-co-PDL NPs were prepared using a modified oil-in water $(\mathrm{o} / \mathrm{w})$ single emulsion solvent evaporation method (29). The results of 18 runs, suggested by Taguchi's L18 orthogonal array, resulted in NPs of size $<150 \mathrm{~nm}$. However, this increases to about 200-300 nm after centrifugation and BSA adsorption. This according to the literature suggests an effective uptake by DCs (15-17). The effects of each factor are discussed in detail below:

Factor D, PVA concentration (range=3.17, rank=1), is the most important factor affecting the particle size. The $\mathrm{S} / \mathrm{N}$ ratios at three levels indicated that particle size almost linearly decreased with increase in surfactant concentration from 2.5 to $10 \% w / v\left(\mathrm{~S} / \mathrm{N}\right.$ ratio, $\left.r^{2}=0.997\right)$. The particle size decreases because at lower concentrations there is inadequate amount of surfactant to cover all the surfaces of PGA-co-PDL NPs (38). The uncovered NPs then tend to aggregate until a point where there is adequate amount of surfactant to cover the total surface area of the aggregated NPs, and form a stable system leading to larger particles. However, with an increase in surfactant concentration it was possible to efficiently cover all the surfaces of NPs thereby stabilizing the system avoiding aggregation and resulting in smaller PGAco-PDL NPs (38). This effect of decrease in particle size with an increase in surfactant concentration, PVA, was also observed by Mitra and Lin (39).

The $\mathrm{S} / \mathrm{N}$ ratios of factor $\mathrm{A}$, molecular weight of the polymer (range=2.19, rank=3), at two levels, suggested a directly proportional relationship with MW of polymer, i.e. the particle size decreases with a decrease in the MW of the polymer. This can also be evident from the lower particle size measurements observed using 14.7 KDa MW polymer (runs 1-9) relative to 24 KDa MW polymer (runs 10-18). As the MW of polymer increases, the viscosity of the polymeric solution also increases, thereby imposing difficulty in breaking them into smaller emulsion droplets when compared to lower MW polymer requiring lower efficiency to breakdown under similar conditions. This increase in size of the 
[Type here]

particles has also been observed by others and is reported to be associated with high MW polymers $(5,40,41)$.

The $\mathrm{S} / \mathrm{N}$ ratios of factor $\mathrm{B}$, volume of organic solvent ( $\mathrm{DCM}$, range $=2.32$, rank $=2$ ), at three levels indicated that particle size almost linearly decreased with increase in volume from 1 to $2 \mathrm{ml}(\mathrm{S} / \mathrm{N}$ ratio, $\left.\mathrm{r}^{2}=0.999\right)$. This decrease in particle size is attributed to the decrease in viscosities of the polymer solution (keeping the amount and MW of polymer constant). This makes it easier to break into smaller emulsion droplets resulting in a decreased particle size as explained above. This effect could also be observed with factor $\mathrm{C}$, volume of 1 st aqueous phase (range $=1.23$, rank $=5$ ), where a decrease in volume increased the viscosity thereby resulting in an increase in particle size.

The $\mathrm{S} / \mathrm{N}$ ratios for factor $\mathrm{E}$, sonication time (range=2.09, rank=4), did not follow any particular trend; however, the $2^{\text {nd }}$ level was found to be the optimum for achieving smaller particle size. The $\mathrm{S} / \mathrm{N}$ ratios for parameters $\mathrm{F}$, stirrer speed (the speed at which the magnetic bar was rotating for evaporation of DCM in the external phase) and G, $2^{\text {nd }}$ PVA concentration have a low range of 0.34 and 0.18 respectively indicating that they have a minimal influence over the size of NPs produced. Therefore, the optimum conditions inferred result in NPs of size suitable for cellular uptake into DC as established in the literature $(15-17,42,43)$.

The adsorption of BSA onto NPs is expected to be mainly driven by hydrophobic, electrostatic (ionic) interactions and hydrogen bonding (44). However, in this study as the NPs, evident from zeta-potential values, are negatively charged and BSA in water is also highly negatively charged (45) suggesting that the electrostatic interactions are minimal and that the adsorption process is dominated by the hydrophobic interactions and hydrogen bonding. The BSA adsorption onto NPs increased with an increase in NP: BSA ratio from 100: 4 to 100: 20, which was expected as the amount of BSA available for adsorption increased. Figure $2 \mathrm{~b}$ suggests that the surface of NPs was saturated with BSA after $1 \mathrm{~h}$ suggesting maximum adsorption with 100: 20 (NP: BSA) BSA loading concentration.

\section{Nanocomposite Microparticles Characterization}

NCMPs were produced by SD using L-leu as a carrier and a dispersibility enhancer. The SEM pictures (Fig. 3) show irregular or wrinkled surface which is due to an excessive build-up of vapour pressure during water evaporation in the SD pro- cess and occurs with hydrophobic amino acids, such as L-Leu $(8,46,47)$.

The release profile shows more than $90 \%$ of the BSA released within $48 \mathrm{~h}$ this is because of weaker hydrophobic interactions between BSA and NPs compared to the strong ionic interactions. Moreover, the identical bands observed for BSA standard and desorbed BSA from NCMPs suggests that protein has maintained its primary structure and was neither degraded nor affect- ed by the adsorption and SD procedure.

The secondary structure of BSA in the formulation was analysed using CD spectroscopy, a valuable technique in analysing the protein structure (31). The BSA released samples confirms the presence of $\alpha$-helix and $\beta$-sheets though decreased compared to standard BSA. However, in protein secondary structure, it is believed that the $\beta$-sheet structure is sometimes observed as a special $\alpha$-helix only with two amino acid residues through stretching resulting from the breakage of hydrogen bond $(37,48)$.

It is established that BSA possesses an enzyme-like activity with the ability to hydrolyse substrates 
[Type here]

suchasp-nitophenylesters $(36,49,50)$. In this study, the released BSA sample retained approximately $77 \%$ of relative residual esterolytic activity com- pared to standard BSA. A reduction in BSA activity to 60\% was also observed by Abbate et al. when released from biohybrid hydrogels (36). The adsorption and desorption process of BSA could have influenced the structure (evident from a decreased helicity determined by $\mathrm{CD}$ ) and thus the activity. However, the retention of $77 \%$ ester hydrolysis activity would encourage the exploration of the delivery system for further usage.

The FPF value suggests an excellent aerosolization performance and deep lung deposition profile. The surface activity of the relatively strong hydrophobic alkyl side chain of L-leu accumulating at the particle surface during SD reduces the surface free energy of the dry powder and cohesive inter-particulate interactions and this might be a plausible explanation for the enhanced dispersibility $(8,23)$. In addition, the dispersibility enhancing property of L-leu resulting from its corrugated surface that reduces the contact points between particles leads to an improved aerosolization characteristic of powders $(22,47,51)$. Similar reports have also demonstrated the enhanced aerosol performance with L-leu containing formulations $(22,47,51,52)$. Moreover, the MMAD values show an efficient delivery of NCMPs containing BSA to the deep lungs mainly to the bronchial-alveolar region (3). A study by Todoroff et al. have shown that more intense specific immune responses could be achieved by targeting the antigen to the deep lungs than to the upper airways (53). Also, Menzel et al. have shown that upon inhalation of Pneumovax ${ }^{\circledR}$, a pneumococcal polysaccharide vaccine, by healthy volunteers the vaccine deposited in the alveolar region displayed increased serum antibody levels compared to that deposited in the larger airways (54). Thus, this deposition to the deep lungs may generate stronger immune responses.

The NGI data suggests a deposition mainly in the bronchial-alveolar region of the lungs (3), thus the cell viability studies were performed on A549 cell line (adenocarcinomic human alveolar basal epithelial cells) and 16HBE14o- cell line (human bronchial epithelial cells). The results show that both the cell lines were tolerant to the NCMPs up to $1.25 \mathrm{mg} / \mathrm{ml}$ concentration encouraging further investigation in animals.

\section{CONCLUSIONS}

PGA-Co-PDL NPs of appropriate size to target DCs were successfully produced using Taguchi L18 orthogonal array DoE. BSA adsorption onto NPs in the ratio of 100: 20 (NP: BSA) for $1 \mathrm{~h}$ at room temperature produced the maximum adsorption of BSA $(10.23 \pm 1.87 \mu \mathrm{g}$ of protein per mg of NPs). The BSA adsorbed NPs were successfully spray-dried using L-leu into NCMPs producing a yield of $\pm 3.17 \%$ and the NCMPs had irregular and corrugated morphology. The BSA released from the NCMPs was shown to be maintaining its structure under SDS- PAGE and CD analysis with 77\% of relative residual esterolytic activity. Moreover, FPF of $76.49 \pm 6.26 \%$ and MMAD of $1.21 \pm 0.67 \mu \mathrm{m}$ values indicate deep lung de- position with NCMPs showing a low toxicity profile. This study suggests that PGA-Co-PDL NCMPs could be used as a novel carrier for pulmonary vaccine delivery.

\section{ACKNOWLEDGMENTS AND DISCLOSURES}

We would like to thank Dr Mark Murphy (Liverpool John Moores University, Liverpool, UK) for his help with confocal microscopy studies 


\section{REFERENCES}

1. Leleux J, Roy K. Micro and nanoparticle-based delivery systems for vaccine immunotherapy: an immunological and materials perspec- tive. Adv Healthc Mater. 2013;2:72-94.

2. Akagi T, Baba M, Akashi M. Biodegradable nanoparticles as vaccine adjuvants and delivery systems: regulation of immune responses by nanoparticle-based vaccine. Adv Polym Sci. 2012;247:31-64.

3. Kunda N, Somavarapu S, Gordon S, Hutcheon G, Saleem I. Nanocarriers targeting dendritic cells for pulmonary vaccine deliv- ery. Pharm Res. 2013;30:325-41.

4. Amorij JP, Saluja V, Petersen AH, Hinrichs WLJ, Huckriede A, Frijlink HW. Pulmonary delivery of an inulin-stabilized influenza subunit vaccine prepared by spray-freeze drying induces systemic, mucosal humoral as well as cell-mediated immune responses in BALB/c mice. Vaccine. 2007;25:8707-17.

5. Thomas C, Rawat A, Hope-Weeks L, Ahsan F. Aerosolized PLA and PLGA nanoparticles enhance humoral, mucosal and cytokine re- sponses to hepatitis B vaccine. Mol Pharm. 2010;8:405-15.

6. Panyam J, Labhasetwar V. Biodegradable nanoparticles for drug and gene delivery to cells and tissue. Adv Drug Deliv Rev. 2003;55:329-47.

7. Kallinteri P, Higgins S, Hutcheon GA, St. Pourçain CB, Garnett MC. Novel functionalized biodegradable polymers for nanoparticle drug delivery systems. Biomacromolecules. 2005;6:188594.

8. Tawfeek H, Khidr S, Samy E, Ahmed S, Murphy M, Mohammed A, et al. Poly(glycerol adipate-co$\omega$-pentadecalactone) spray-dried mi- croparticles as sustained release carriers for pulmonary delivery. Pharm Res. 2011;28:2086-97.

9. Tawfeek HM, Evans AR, Iftikhar A, Mohammed AR, Shabir A, Somavarapu S, et al. Dry powder inhalation of macromolecules using novel PEG-co-polyester microparticle carriers. Int J Pharm. 2013;441:611-9.

10. Thompson CJ, Hansford D, Higgins S, Rostron C, Hutcheon GA, Munday DL. Evaluation of ibuprofen-loaded microspheres prepared from novel copolyesters. Int J Pharm. 2007;329:53-61.

11. Duncan G, Jess TJ, Mohamed F, Price NC, Kelly SM, Van der Walle CF. The influence of protein solubilisation, conformation and size on the burst release from poly(lactide-co-glycolide) microspheres. J Control Release. 2005;110:34-48.

12. Peek LJ, Middaugh CR, Berkland C. Nanotechnology in vaccine delivery. Adv Drug Deliv Rev. 2008;60:915-28.

13. Saleem IY, Vordermeier M, Barralet JE, Coombes AGA. Improving peptide-based assays to differentiate between vaccination and myco- bacterium bovis infection in cattle using nanoparticle carriers for adsorbed antigens. J Control Release. 2005;102:551-61.

14. Sou T, Meeusen EN, De Veer M, Morton DA V, Kaminskas LM, McIntosh MP. New developments in dry powder pulmonary vaccine delivery. Trends Biotechnol. 2011;29:191-8.

15. Manolova V, Flace A, Bauer M, Schwarz K, Saudan P, Bachmann MF. Nanoparticles target distinct dendritic cell populations accord- ing to their size. Eur J Immunol. 2008;38:1404-13.

16. Kim H, Uto T, Akagi T, Baba M, Akashi M. Amphiphilic poly(amino acid) nanoparticles induce size-dependent dendritic cell maturation. Adv Funct Mater. 2010;20:3925-31. 
17. Foged C, Brodin B, Frokjaer S, Sundblad A. Particle size and surface charge affect particle uptake by human dendritic cells in an in vitro model. Int J Pharm. 2005;298:315-22.

18. Bilati U, Allémann E, Doelker E. Poly(D,L-lactide-co-glycolide) protein-loaded nanoparticles prepared by the double emulsion meth- od-processing and formulation issues for enhanced entrapment efficiency. J Microencapsul. 2005;22:205-14.

19. Li X, Deng X, Yuan M, Xiong C, Huang Z, Zhang Y, et al. Investigation on process parameters involved in preparation of poly-dl-lactide-poly(ethylene glycol) microspheres containing Leptospira Interrogans antigens. Int J Pharm. 1999;178:245- 55.

20. Sanad R, Abdel Malak N, El-Bayoomy T, Badawi AA. Preparation and characterization of oxybenzone-loaded solid lipid nanoparticles (SLNs) with enhanced safety and sunscreening efficacy: SPF and UVA-PF. Drug Discov Ther. 2010;4:472-83.

21. Stevanovic M, Uskokovic D. Poly(lactide-co-glycolide)-based micro and nanoparticles for the controlled drug delivery of vitamins. Curr Nanosci. 2009;5:1-14.

22. Li H-Y, Seville PC, Williamson IJ, Birchall JC. The use of amino acids to enhance the aerosolization of spray-dried powders for pul- monary gene therapy. J Gene Med. 2005;7:343-53.

23. Seville PC, Learoyd TP, Li H-Y, Williamson IJ, Birchall JC. Amino acid-modified spray-dried powders with enhanced aerosolization properties for pulmonary drug delivery. Powder Technol. 2007;178:40-50.

24. Bosquillon C, Lombry C, Préat V, Vanbever R. Influence of formu- lation excipients and physical characteristics of inhalation dry pow- ders on their aerosolization performance. J Control Release. 2001;70:329-39.

25. Al-fagih IM, Alanazi FK, Hutcheon GA, Saleem I. Recent advances using supercritical fluid techniques for pulmonary administration of macromolecules via dry powder formulations. Drug Deliv Lett. 2011;1:128-34.

26. Bailey MM, Berkland CJ. Nanoparticle formulations in pulmonary drug delivery. Med Res Rev. 2009;29:196-212.

27. Soppimath KS, Aminabhavi TM, Kulkarni AR, Rudzinski WE. Biodegradable polymeric nanoparticles as drug delivery devices. J Control Release. 2001;70:1-20.

28. Thompson CJ, Hansford D, Higgins S, Hutcheon GA, Rostron C, Munday DL. Enzymatic synthesis and evaluation of new novel $\omega$-pentadecalactone polymers for the production of biodegradable microspheres. J Microencapsul. 2006;23: 213-26.

29. Pinto Reis C, Neufeld RJ, Ribeiro AJ, Veiga F. Nanoencapsulation I. Methods for preparation of drugloaded polymeric nanoparticles. Nanomedicine: NBM. 2006;2:8-21.

30. Do KK, Kim SH, Kim HT. Applying the Taguchi method to the optimization for the synthesis of TiO2 nanoparticles by hydrolysis of TEOT in micelles. Colloids Surf A Physicochem Eng Asp. 2005;254: 99-105.

31. Greenfield NJ. Using circular dichroism spectra to estimate protein secondary structure. Nat Protoc. 2007;1:2876-90.

32. Henzler Wildman KA, Lee D-K, Ramamoorthy A. Mechanism of lipid bilayer disruption by the human antimicrobial peptide, LL-37†. Biochemistry. 2003;42:6545-58.

33. Whitmore L, Woollett B, Miles AJ, Janes RW, Wallace BA. The protein circular dichroism data bank, a web-based site for access to circular dichroism spectroscopic data. Structure (Lond Engl 1993). 2010;18:1267-9.

34. Whitmore L, Wallace BA. Protein secondary structure analyses from circular dichroism spectroscopy: methods and reference databases. Biopolymers. 2008;89:392-400.

35. Whitmore L, Wallace BA. DICHROWEB, an online server for protein secondary structure analyses from circular dichroism spec- troscopic data. Nucleic Acids Res. 2004;32:W668-73. 


\section{[Type here]}

36. Abbate V, Kong X, Bansal SS. Photocrosslinked bovine serum albumin hydrogels with partial retention of esterase activity. Enzym Microb Technol. 2012;50:130-6.

37. Zhang J, Ma X, Guo Y, Yang L, Shen Q, Wang H, et al. Size- controllable preparation of bovine serum albumin-conjugated PbS nanoparticles. Mater Chem Phys. 2010;119:112-7.

38. Douglas SJ, Illum L, Davis SS. Particle size and size distribution of poly(butyl 2-cyanoacrylate) nanoparticles. II. Influence of stabilizers. J Colloid Interface Sci. 1985;103:154-63.

39. Mitra A, Lin S. Effect of surfactant on fabrication and characteriza- tion of paclitaxel-loaded polybutylcyanoacrylate nanoparticulate de- livery systems. J Pharm Pharmacol. 2003;55:895-902.

40. Jalil R, Nixon JR. Microencapsulation using poly (L-lactic acid) III: effect of polymer molecular weight on the microcapsule properties. J Microencapsul. 1990;7:41-52.

41. Mittal G, Sahana DK, Bhardwaj V, Ravi Kumar MN V. Estradiol loaded PLGA nanoparticles for oral administration: effect of polymer molecular weight and copolymer composition on release behavior in vitro and in vivo. J Control Release. 2007;119:77-85.

42. Joshi V, Geary S, Salem A. Biodegradable particles as vaccine delivery systems: size matters. AAPS J. 2013;15:85-94.

43. Sloat BR, Sandoval MA, Hau AM, He Y, Cui Z. Strong antibody responses induced by protein antigens conjugated onto the surface of lecithin-based nanoparticles. J Control Release. 2010;141:93-100.

44. Yoon J-Y, Kim J-H, Kim W-S. The relationship of interaction forces in the protein adsorption onto polymeric microspheres. Colloids Surf A Physicochem Eng Asp. 1999;153:413-9.

45. Regev O, Khalfin R, Zussman E, Cohen Y. About the albumin structure in solution and related electro-spinnability issues. Int J Biol Macromol. 2010;47:261-5.

46. Li H-Y, Neill H, Innocent R, Seville P, Williamson I, Birchall JC. Enhanced dispersibility and deposition of spray-dried pow- ders for pulmonary gene therapy. J Drug Target. 2003;11: 42532.

47. Sou T, Kaminskas LM, Nguyen T-H, Carlberg R, McIntosh MP, Morton DA V. The effect of amino acid excipients on morphology and solid-state properties of multi-component spray-dried formula- tions for pulmonary delivery of biomacromolecules. Eur $\mathrm{J}$ Pharm Biopharm. 2013;83:234-43.

48. Yang L, Guo Y, Ma X, Hu Z, Zhu S, Zhang X, et al. Cooperativity between pepsin and crystallization of calcium carbonate in distilled water. J Inorg Biochem. 2003;93:197-203.

49. Tildon JT, Ogilvie JW. The esterase activity of bovine mercaptalbumin. The reaction of the protein with p-nitrophenyl acetate. J Biol Chem. 1972;247:1265-71.

50. Córdova J, Ryan JD, Boonyaratanakornkit BB, Clark DS. Esterase activity of bovine serum albumin up to $160^{\circ} \mathrm{C}$ : a new benchmark for biocatalysis. Enzym Microb Technol. 2008;42:278-83.

51. Feng AL, Boraey MA, Gwin MA, Finlay PR, Kuehl PJ, Vehring R. Mechanistic models facilitate efficient development of leucine con- taining microparticles for pulmonary drug delivery. Int $\mathrm{J}$ Pharm. 2011;409:156-63.

52. Najafabadi AR, Gilani K, Barghi M, Rafiee-Tehrani M. The effect of vehicle on physical properties and aerosolization behaviour of disodium cromoglycate microparticles spray dried alone or with l- leucine. Int J Pharm. 2004;285:97-108.

53. Todoroff J, Ucakar B, Inglese M, Vandermarliere S, Fillee C, Renauld J-C, et al. Targeting the deep lungs, poloxamer 407 and a $\mathrm{CpG}$ oligonucleotide optimize immune responses to mycobacterium tuberculosis antigen 85A following pulmonary delivery. Eur J Pharm Biopharm. 2013;84(1):40-8.

54. Menzel M, Muellinger B, Weber N, Haeussinger K, Ziegler- Heitbrock L. Inhalative vaccination with pneumococcal polysaccha- ride in healthy volunteers. Vaccine. 2005;23:5113-9 
[Type here] 